\title{
Uma escola de pensamento keynesiano-estruturalista no Brasil?
}

\section{LUIZ CARLOS BRESSER-PEREIRA*}

A new Keynesian-struturalist school of thought is emerging in Brazil. It is formed by a Structuralist Development Macroeconomics that offers scientific explanation to New Developmentalism - a national development strategy. In this intervention the author delineates its main theoretical claims and policies.

Keywords: macroeconomics; structuralism; developmentalism; history of economic thought

JEL classification: B22; B31.

Há indicações cada vez mais claras de que está surgindo no Brasil uma nova escola de pensamento econômico - uma Escola Keynesiano-estruturalista do Desenvolvimento - que tem como fundamento teórico uma Macroeconomia Estruturalista do Desenvolvimento e como proposta de política econômica ou, mais amplamente, como estratégia nacional de desenvolvimento, o Novo Desenvolvimentismo. Esta nova realidade começou a se configurar no início dos anos 2000 quando um grupo de economistas keynesianos e estruturalistas, insatisfeitos com as baixas taxas de crescimento do Brasil, decidiu enfrentar o mainstream teórico neoclássico (o modelo de equilíbrio geral e a macroeconomia das expectativas racionais) e o consenso de Washington dominantes na teoria econômica ensinada nas universidades e na política econômica.

Em um primeiro momento, a partir de 2003, esse grupo definiu um conjunto de políticas econômicas, o novo desenvolvimentismo, não obstante o establishment econômico neoliberal procurasse tornar a palavra "desenvolvimentismo" pejorativa, associando-a ao populismo e ao estatismo, e estabeleceu como objeto de seu estudo e de suas propostas os países de renda média ou

\footnotetext{
* Emeritus professor of Getulio Vargas Foundation. E-mail: bresserpereira@gmail.com.
} 
emergentes. Ao mesmo tempo compreendeu que as ideias pós-keynesianas, desenvolvidas nos Estados Unidos, ou seja, em uma realidade muito diferente da de um país de renda média como o Brasil, não eram suficientes para fundamentar as propostas de política macroeconômica visando estabilidade e crescimento. Assim também havia deixado de ser suficiente o conjunto de ideias que caracterizou a teoria estruturalista do desenvolvimento dominante entre os anos 1940 e 1960. Muitas de suas ideias necessitavam reformulação. Faltava-lhes uma abordagem macroeconômica sistemática, porque referiam-se a países que se encontravam agora em uma etapa diferente de desenvolvimento, e porque a sociedade mundial estava agora definida pela globalização, na qual os mercados se abriram e os países de renda média passaram a exportar manufaturados para todo o mundo.

Foram estas considerações que levaram os economistas heterodoxos brasileiros a desenvolver suas novas ideias. Foram essas ideias que eu procurei sintetizar em Globalização e competição (2009). Mas foi depois de o livro ter sido publicado que ficou claro para mim que as teorias resumidas nesse livro constituíam um todo teórico integrado e original - uma macroeconomia estruturalista do desenvolvimento - que estabelecia as bases para uma nova escola de pensamento. Quem me chamou atenção para esse fato foi Robert Boyer, no prefácio que escreveu para a edição francesa de meu livro. Que nome dar para o conjunto de novas teorias, e para a nova escola de pensamento? Eu sabia que estávamos desenvolvendo uma macroeconomia do desenvolvimento, mas apenas recentemente acrescentei o "estruturalista" para designá-la.

A macroeconomia estruturalista do desenvolvimento é uma teoria macroeconômica porque afirma que o principal ponto de estrangulamento do desenvolvimento econômico não está do lado da demanda mas do lado da oferta, e porque está baseada no pensamento de John Maynard Keynes e Michael Kalecki. É uma teoria estruturalista porque adota o método histórico-dedutivo, porque entende o desenvolvimento como mudança estrutural ou industrialização, porque está associada ao pensamento dos grandes economistas clássicos, principalmente Adam Smith e Karl Marx, dos economistas historicistas alemães e dos institucionalistas americanos, e dos economistas estruturalistas do desenvolvimento como Rosenstein-Rodan, Gunnar Myrdal, Ragnar Nurkse, Arthur Lewis, Raul Prebisch, Celso Furtado, Hans Singer e Albert Hirschman, e porque esse conjunto sistemático de ideias tem em seu núcleo duas tendências estruturais: a tendência dos salários a crescerem menos do que a produtividade e a tendência à sobreapreciação cíclica da taxa de câmbio.

As ideias centrais da macroeconomia estruturalista do desenvolvimento e do novo desenvolvimentismo podem ser resumidas em algumas proposições: 


\section{Pressuposto metodológico}

1. A boa teoria econômica ou a economia política é a dos grandes economistas clássicos, keynesianos, e estruturalistas. É uma teoria que usa o método histórico-dedutivo, generalizando e deduzindo a partir da experiência empírica ou histórica, e não a partir de um pressuposto de racionalidade.

\section{Pressuposto microeconômico}

2. A teoria econômica só nasceu quando as sociedades mais avançadas realizaram sua revolução capitalista e, a partir de então, além de serem coordenadas pelo Estado ou, mais amplamente, pelas instituições, passaram também a sê-lo por uma instituição especial - o mercado.

3. Todo mercado precisa ser regulado, mas quanto mais amplos e mais complexos forem eles, maior será a necessidade de regulá-los para que desempenhem bem seu papel de coordenação econômica.

4. Por isso, ao mesmo tempo em que se defenderá a concorrência e, portanto, mercados competitivos, os mercados deverão ser bem regulados, principalmente os mercados financeiros, e, nestes, principalmente os grandes bancos, exigindo-se deles elevados coeficientes de capital.

\section{Desenvolvimento econômico estrutural}

5. O desenvolvimento econômico é um processo de acumulação de capital com incorporação de progresso técnico que, no médio prazo, implica aumento da produtividade e dos salários ou do padrão de vida médio da população.

6. O aumento da produtividade ocorre internamente a cada setor e, estruturalmente, através da transferência de mão de obra para setores caracterizados por valor adicionado per capita crescentemente mais altos ("industrialização").

7. Inicialmente, nos processos históricos de formação do Estado-nação e de revolução industrial que definem essa revolução, o desenvolvimento econômico se confunde com revolução capitalista.

Investimento, taxa de lucro e de juros

8. O desenvolvimento econômico depende essencialmente da taxa de investimento.

9. A taxa de investimento não depende da existência de poupança prévia, já que no modelo keynesiano é o investimento que determina a poupança, mas (a) da existência de oportunidades de investimentos lucrativos para os empresários, (b) da existência de um sistema financeiro que lhes garanta crédito, e (c) de um razoável volume de investimento público. 
10. As oportunidades de investimentos lucrativos, por sua vez, dependem da taxa de lucro esperada e da taxa de juros ou do custo do capital.

11. A taxa esperada de lucro depende da existência de demanda interna e da possibilidade de que as empresas eficientes logrem exportar e, assim, se aproveitar da demanda externa.

12. Uma taxa de juros moderada depende da saúde financeira do Estado e de uma política monetária voltada não apenas para a estabilidade de preços mas também para o equilíbrio cambial e o pleno emprego ou o crescimento.

\section{Abordagem do lado da demanda}

13. O desenvolvimento econômico depende também da eficiência ou produtividade dos investimentos, ou seja, da relação produto-capital, a qual reflete fatores do lado da oferta como educação, desenvolvimento tecnológico, boas instituições e boa infraestrutura.

14. Raramente esses fatores constituem ponto de estrangulamento para o crescimento, enquanto que a insuficiência de demanda interna e a falta de acesso à demanda externa são fenômenos crônicos nos países de renda média que deprimem as oportunidades de investimentos lucrativos.

15. O investimento público recomendável para países de renda média é menor do que o necessário para que um país pobre ou um país pré-industrial possa desencadear sua revolução industrial, mas é importante na composição da taxa total de investimento e no estímulo aos investimentos privados.

16. Se o investimento público recomendável for, digamos, um quarto do investimento total, para que seja capaz de investir essa soma sem causar inflação, o Estado deverá ser financeiramente saudável, ou seja, deverá ter uma dívida razoavelmente pequena, e deverá apresentar uma poupança pública positiva.

\section{Salários e demanda interna}

17. A demanda interna depende desses investimentos públicos e, principalmente, de que os salários cresçam aproximadamente à mesma taxa da produtividade.

18. Entretanto, uma primeira tendência estrutural - a tendência dos salários crescerem a uma taxa menor que a da produtividade - deprime a demanda interna e exige política econômica corretora em termos de política de rendas e/ou de aumento da despesa social do Estado (salários indiretos).

19. Essa tendência só deixa de ser importante quando o país alcança o “ponto Lewis”, ou seja, quando não é mais razoável se falar em existência de "oferta ilimitada de mão de obra" no país. 


\section{Câmbio, demanda e desenvolvimento}

20. Dado o fato de que o país de renda média já é exportador de manufaturados de que os salários são mais baixos do que nos países ricos, a demanda externa depende menos dos ciclos de prosperidade e recessão do resto do mundo e mais de um "interruptor" - de uma taxa de câmbio competitiva que "ligue" as empresas tecnologicamente mais sofisticadas, que geram maior valor adicionado per capita à demanda externa.

21. A relação entre uma taxa de câmbio competitiva e o desenvolvimento econômico está no fato de que uma taxa de câmbio sobreapreciada "desliga" as empresas eficientes do país da demanda externa, anulando, assim, a causa principal do catching up - a existência de mão de obra relativamente barata - ao mesmo tempo em que permite que empresas estrangeiras com custo mais elevado acessem a demanda interna do país.

22. Países emergentes que não administram sua taxa de câmbio raramente contam com uma taxa de câmbio competitiva devido ao fato de que a doença holandesa deprime essa taxa de forma permanente, enquanto que entradas excessivas de capitais externos a apreciam ciclicamente.

23. Uma taxa de câmbio é competitiva quando torna a demanda externa acessível para empresas que utilizem tecnologia no estado da arte mundial. Denominamo-la taxa de câmbio de "equilíbrio industrial".

\section{Doença holandesa}

24. A doença holandesa é uma sobreapreciação permanente da taxa de câmbio caracterizada por uma taxa de câmbio de "equilíbrio corrente" mais apreciada do que a taxa de câmbio de "equilíbrio industrial" (aquela que torna viáveis as empresas que usam tecnologia de ponta).

25. Quanto maior for a diferença entre a taxa de câmbio de equilíbrio industrial e a de equilíbrio corrente, mais grave será a doença holandesa.

26. A origem da doença holandesa são rendas ricardianas: a existência de recursos naturais abundantes e baratos que permitem a produção e exportação de forma lucrativa de commodity (o petróleo, por exemplo) cujo preço internacional é substancialmente maior do que o custo de produção observado nos países menos eficientes admitidos no mercado (ou que apresentam o maior custo marginal do mercado).

27. Assumindo-se, para simplificar, que uma única commodity origina a doença holandesa, a taxa de câmbio do país será a taxa de câmbio de equilíbrio corrente. É esta taxa que viabiliza as exportações dessa commodity e é também a taxa que equilibra intertemporalmente a conta corrente do país, já que será ela o único bem exportável. Todos os demais bens produzidos com eficiência no país não serão exportáveis 
porque exigem taxa mais depreciada: a taxa de câmbio de equilíbrio industrial.

28. Devido à apreciação do câmbio causada pelas rendas ricardianas, estas não são apropriadas pelo produtor e exportador da commodity, mas pela sociedade sob a forma de preços muito baixos para tudo o que for importado. Em contrapartida, não há transferência de renda para setores com valor adicionado per capita mais alto, e o país não se industrializa.

29. De acordo com o conceito ampliado de doença holandesa, um país que tenha mão de obra barata e leque salarial substancialmente maior do que o existente nos países ricos terá doença holandesa, porque os bens que usam apenas mão de obra não qualificada e barata definirão a taxa de câmbio em um nível mais apreciado do que o necessário para as indústrias sofisticadas que usam técnicos e engenheiros.

30. Dependendo do estágio de desenvolvimento do país, a doença holandesa inviabiliza a industrialização, ou, se o país logrou no passado neutralizar a doença holandesa e se industrializou, causa sua desindustrialização. Dependendo de sua gravidade, o grau da desindustrialização será maior ou menor.

\section{Tendência à sobreapreciação cíclica da taxa de câmbio}

31. Uma segunda tendência estrutural - a tendência à sobreapreciação cíclica da taxa de câmbio - faz com que a taxa de câmbio não seja equilibrada pelo mercado, não flutue em torno da taxa de câmbio que equilibra intertemporalmente a conta corrente de forma suave como afirma a teoria convencional, nem de forma volátil como afirma a teoria keynesiana, mas seja determinada por crises cíclicas de balanço de pagamentos.

32. Enquanto nos países ricos as crises financeiras são geralmente crises bancárias, nos países em desenvolvimento que se endividam em moeda forte são geralmente crises de balanço de pagamentos caracterizadas pela súbita suspensão da rolagem da dívida externa pelos credores externos.

33. As crises de balanço de pagamentos ou currency crises são precedidas, sucessivamente, por aumento do gasto público e do consumo privado, aumento das dívidas pública e privada e correspondente aumento do endividamento público e privado, déficits em conta corrente, aumento do endividamento externo, rolagem da dívida para pagamento do principal, rolagem da dívida para pagar também os juros, perda de confiança, e desembocam em violenta depreciação da taxa de câmbio (sudden stop). 


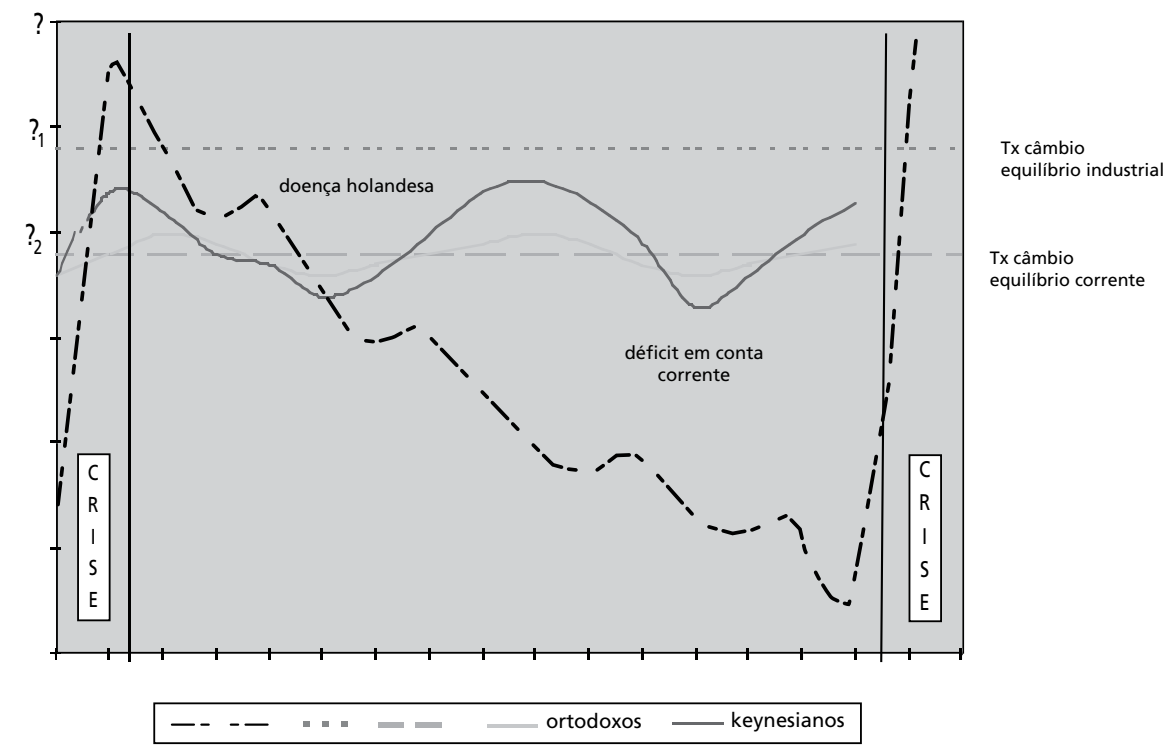

Figura 1: Tendência cíclica à sobreapreciação da taxa de câmbio

A linha - - - - representa a tendência cíclica à sobreapreciação cambial. Depois de uma crise de balanço de pagamentos ou sudden stop, ela aprecia, primeiro, puxada até o equilíbrio corrente pela doença holandesa, e, a partir dela, para a área de déficit em conta corrente, pelas entradas de capital.

34. A tendência à sobreapreciação cíclica da taxa de câmbio é consequência de dois fatores estruturais que se somam: a doença holandesa, que puxa o câmbio para o equilíbrio corrente e impede a industrialização, e pelas entradas de capitais que financiam déficits em conta corrente e apreciam a taxa de câmbio, puxando-a para abaixo do equilíbrio corrente.

35. As entradas de capital causam, sucessivamente, aumento do consumo, substituição da poupança interna pela externa (de forma que a taxa de investimento aumenta pouco), fragilidade financeira e crise de balanço de pagamentos.

36. As entradas de capitais externos e a decorrente apreciação cambial têm uma causa estrutural - a atração de capitais devido a taxas de lucro e de juros estruturalmente mais elevadas existentes nos países em desenvolvimento pela escassez relativa de capitais. Mas esta apreciação é agravada por políticas e práticas geralmente adotadas nesses países: (a) política de crescimento com poupança externa (déficits em conta corrente) com o objetivo de aumentar a taxa de investimento do país, (b) política de abertura da conta de capitais ou de liberalização financeira para impedir a "repressão financeira" e provocar o "aprofundamento do capital" que, na prática, corresponde à elevação da taxa de juros interna e à perda do controle da taxa de câmbio, (c) política de âncora cambial para combater a inflação, (d) prática do "carry trade" pelos 
especuladores financeiros para ganhar duplamente com os juros altos e a tendência à sobreapreciação cíclica da taxa de câmbio, (f) modelo dos "dois hiatos", que afirma que ao hiato da falta de poupança interna existe um hiato de dólares que justificaria o financiamento externo, (g) lei de Thirwall, que corretamente limita o crescimento do PIB ao aumento das exportação quando dela se deduz a necessidade de financiamento externo; e (h) a prática de "populismo cambial" - do político procurar se eleger graças à apreciação cambial que aumenta artificialmente os salários e reduz a inflação.

37. A política de atrair capitais externos e a de não limitar sua entrada são, portanto, causas exógenas da apreciação cambial.

38. Que essas políticas, práticas e justificações teóricas apreciem o câmbio e causem fragilidade financeira e afinal crise de balanço de pagamentos é óbvio. Menos óbvio é que a principal delas, a política de crescimento com poupança externa, antes de causar fragilidade financeira e crise, provoca mais o aumento do consumo do que do investimento, caracterizando-se por elevada taxa de substituição da poupança interna pela externa. Em consequência ocorre endividamento externo sem que haja aumento correspondente da produção e da capacidade de exportar.

39. A elevada taxa de substituição da poupança interna pela externa é consequência, do lado da renda, do aumento artificial dos salários causado pela apreciação cambial, do decorrente aumento do consumo, e de uma geralmente alta propensão marginal a consumir; do lado da demanda, é consequência da diminuição das oportunidades de investimento lucrativo, da diminuição dos investimentos e, portanto, da taxa de poupança interna.

\section{Inflação}

40. A inflação não é causada pelo aumento da oferta de moeda (que é endógena), nem é necessariamente consequência de demanda aquecida. Pode ser também causada por elevação de custos, poder de monopólio, e ter componente inercial significativo devido à indexação formal e informal da economia.

41. O controle da inflação não é o único objetivo da política econômica. Crescimento e distribuição são também objetivos a serem perseguidos.

\section{Novo desenvolvimentismo export-led}

42. A tese de que deve haver para cada objetivo um instrumento é falsa. Os policymakers bem-sucedidos usam pragmaticamente múltiplos instrumentos para atingir objetivos nem sempre plenamente compatíveis.

43. O novo desenvolvimentismo é o nome de uma estratégia nacional de desenvolvimento ou de competição que cria oportunidades de investimento lucrativo.

44. Ela está baseada na experiência bem sucedida dos países asiáticos dinâ- 
micos que adotam uma estratégia export-led (puxada para as exportações) que lhes permite aumentar a taxa de investimento e mudar de patamar a taxa de crescimento econômico, aproveitando-se de sua mão de obra barata.

45. Uma vez aumentado o patamar de investimento e de crescimento, os países passam a alternar a política export-led com a wage-led (puxada pelos salários), porque precisam neutralizar tanto a tendência à sobreapreciação cíclica da taxa de câmbio quanto a tendência dos salários a crescerem menos do que a produtividade.

\section{Neutralização da doença holandesa e das duas tendências}

46. A neutralização da tendência dos salários crescerem menos do que a produtividade se faz principalmente por política de salário mínimo, de renda mínima e de aumento da despesa social.

47. A neutralização da doença holandesa se faz principalmente através da imposição de imposto de exportações, porque, dado o preço internacional da commodity, esse imposto desloca a sua curva de oferta em relação à taxa de câmbio para a esquerda, de forma que seus produtores só continuam dispostos a produzir as mesmas quantidades se a taxa de câmbio compensar o imposto por cada moeda forte exportada.

48. A neutralização da doença holandesa implica superávit em conta corrente que deve, preferivelmente, ser usado para constituir fundo soberano. Pode, entretanto, também ser utilizado para gasto público, mas com muita cautela.

49. A constituição de fundo soberano implica superávit fiscal. Por isso, países que neutralizam sua doença holandesa, e esta é grave, devem apresentar superávit fiscal.

50. A neutralização das entradas de capitais ou a administração da taxa de câmbio se faz por compra de dólares e aumento de reservas, e, principalmente, por controles de capitais, preferivelmente impostos sobre as entradas em lugar de controles quantitativos.

51. A administração da taxa de câmbio não é impossibilitada pelo triângulo de impossibilidades, que é logicamente correto, mas peca pela falta de áreas cinzentas e por ser enviesado contra essa administração. O pressuposto de que os fluxos de capitais são livres e devem permanecer livres é falso, de forma que não se pode concluir do triângulo que seja necessário renunciar à política monetária ou renunciar à política cambial, sendo, então, preferível renunciar à segunda. Em termos práticos, os países não situam essas três políticas nas pontas do triângulo, e fazem compromissos (compromises) entre elas.

\section{Controle da inflação e dos endividamentos}

52. O controle da inflação se faz através de política fiscal, de política de juros e de política de crédito. Evita-se o abuso da política de juros para 
se garantir a manutenção da taxa de juros em nível razoável sem prejuízo da política anticíclica de controle da inflação.

53. Além do controle da inflação é necessário limitar os aumentos especulativos dos preços dos ativos.

54. A prevenção das crises financeiras é feita através da política de crescimento com poupança interna, da neutralização da tendência à sobreapreciação cíclica da taxa de câmbio, e da regulação financeira que implica políticas que limitem todos os tipos de endividamento: externo e interno, público, das empresas, dos bancos e das famílias.

Creio que esse conjunto teórico é suficientemente sistemático e amplo e que contém elementos suficientemente novos para se constituir em uma escola teórica de pensamento. É uma escola keynesiano-estruturalista que, naturalmente, dá grande importância às instituições, mas não precisa explicitá-las em sua designação porque o estruturalismo reserva um papel central para elas. É uma escola que nasce brasileira, mas aproveita amplamente a experiência internacional, principalmente a dos países de renda média. É uma escola que conta com contribuição de notáveis economistas, sociólogos e cientistas políticos de todo o mundo, como é possível ver consultando a lista dos subscritores das Then Theses on New Developmentalism (Dez Teses sobre o Novo Desenvolvimentismo) definidas em 2010 . 